$\Gamma$ енетические маркеры развития поражения суставов у больных псориазом. Часть II: Гены системы HLA

(С) Кубанов А.А., Чикин В.В., Карамова А.Э., Знаменская Л.Ф., Артамонова О.Г. *, Вербенко Д.А.

Государственный научный центр дерматовенерологии и косметологии

107076, Россия, г. Москва, ул. Короленко, д. 3, стр. 6

Псориаз артропатический (псориатический артрит) часто приводит к развитию тяжелых исходов анкилозов, деформаций пораженных суставов с выраженным нарушением их функций и инвалидности. Раннее выявление больных псориазом с повышенным риском развития псориатического артрита с целью его своевременной диагностики и раннего начала терапии может предотвратить развитие тяжелых исходов болезни. Считается, что наибольший индивидуальный генетический вклад в фрормирование предрасположенности к наследственным заболеваниям с полигенным наследованием вносят гены системы HLA. В обзоре литературы рассмотрены полиморфизмы генов системы $H L A$, ассоциированные с развитием псориатического артрита у больных псориазом. Определены аллели $H L A$, способствующие развитию псориатического артрита и его отдельных фрорм. Выделены аллели $H L A$, которые обладают протективным эффектом в отношении развития псориатического артрита.

Ключевые слова: псориатический артрит, гены системы HLA, HLA-B²7.

Конфрликт интересов: авторы данной статьи подтвердили отсутствие конфрликта интересов, о котором необходимо сообщить.

Источник фринансирования: работа выполнена за счет финансирования по месту работы авторов.

Для цитирования: Кубанов А.А., Чикин В.В., Карамова А.Э., Знаменская Л.Ф., Артамонова О.Г., Вербенко Д.А. Генетические маркеры развития поражения суставов у больных псориазом. Часть II: Гены системы HLA.

Вестник дерматологии и венерологии. 2021;97(5):06-17. doi: https://doi.org/10.25208/vdv1269 


\section{Tenetic markers for psoriatic arthritis among patients with psoriasis. Part II: HLA genes}

(c) Alexey A. Kubanov, Vadim V. Chikin, Arfenya E. Karamova, Lyudmila F. Znamenskaya, Olga G. Artamonova*, Dmitry A. Verbenko

State Research Center of Dermatovenereology and Cosmetology

Korolenko str., 3, bldg 6, 107076, Moscow, Russia

Psoriatic arthritis often leads to the development of severe outcomes - ankylosis, deformities of the affected joints with severe impairment of their functions and disability. Early identification of patients with psoriasis with an increased risk of developing psoriatic arthritis for the purpose of its timely diagnosis and early initiation of therapy can prevent the development of severe disease outcomes. It is believed that the genes of the HLA system make the greatest individual genetic contribution to the formation of a predisposition to hereditary diseases with polygenic inheritance. The literature review considers the polymorphisms of the genes of the HLA system, associated with the development of psoriatic arthritis, in patients with psoriasis. The $H L A$ alleles that contribute to the development of psoriatic arthritis and its individual forms have been identified. HLA alleles have been identified, which have a protective effect against the development of psoriatic arthritis.

Keywords: psoriatic arthritis, HLA genes, HLA-B*27.

Conflict of interest: the authors declare that there are no obvious and potential conflicts of interest associated with the publication of this article.

Source of funding: the work was done through financing at the place of work of the authors.

For citation: Kubanov AA, Chikin VV, Karamova AE, Znamenskaya LF, Artamonova OG, Verbenko DA. Genetic markers for psoriatic arthritis among patients with psoriasis. Part II: HLA genes. Vestnik Dermatologii i Venerologii. 2021;97(5):06-17. doi: https://doi.org/10.25208/vdv1269 


\section{Введение}

Псориаз является Т-клеточно-опосредованным заболеванием, в основе которого лежит активация воспалительной оси ИЛ-23/Th17-лимфоциты [1-5]. По имеющимся оценкам, у 20-30\% больных псориазом развивается псориатический артрит - хроническое воспалительное заболевание суставов, позвоночника и энтезисов с полигенным наследованием. Прогнозирование развития псориатического артрита у больных псориазом является актуальной проблемой, решение которой возможно путем определения генетических биомаркеров, предрасполагающих к развитию заболевания.

Считается, что наибольший индивидуальный генетический вклад в формирование предрасположенности к наследственным заболеваниям с полигенным наследованием вносят гены системы HLA, которые рассматриваются как наиболее значимые фракторы риска развития большинства аутоиммунных/аутовоспалительных заболеваний $[6,7]$.

Основная функция белков главного комплекса гистосовместимости HLA заключается в регуляции иммунного ответа организма на чужеродные антигены и осуществлении иммунного надзора путем обнаружения Т-лимсоцитами клеток-хозяев, подвергшихся изменениям в результате воздействия инфекционных агентов или опухолевой трансформации [8-10]. Гены системы HLA представляют собой комплекс, расположенный на коротком плече хромосомы 6 (6p21.31), занимающий область размером 7,6 Mb [11]. Локус HLA считается наиболее полиморфным в геноме человека, насчитывая десятки тысяч аллелей [12]. Эти гены кодируют белки HLA (Human Leukocyte Antigen), или человеческие лейкоцитарные антигены, также известные как основной комплекс гистосовместимости человека (МНС).

Выделяют 3 класса генов HLA - I, II и III. Известно 3 локуса генов HLA класса I, каждый из этих локусов обозначается буквой (A, B, C) [13] и кодирует соответствующие белки HLA-A, HLA-B и HLA-C. Локусы генов $H L A$ класса II обозначают как $H L A-D P, H L A-D Q$ и $H L A-D R$, кодируют соответствующие классические белки HLA класса II. Суффриксы A и B (DRA или DRB) используются для обозначения генов HLA класса II, кодирующих полипептидные $\alpha$ - и $\beta$-цепи белков HLA класса II соответственно [13]. Дополнительные локусы, кодирующие альтернативные цепи HLA-DR $\beta$, которые присутствуют в некоторых гаплотипах, обозначаются цифрами (например, DRB4). Известны также гены, кодирующие неклассические белки HLA класса I и II, к которым относят HLA-F, E, H, X, DN, DO и DM [14, 9]. Примером белков, которые кодируются генами $H L A$ класса III, является система комплемента [9].

За обозначением локуса $H L A$ I и II классов следуют знак " ${ }^{*}$ - звездочка» и несколько пар цифр, разделенных двоеточиями. Эти пары цифр в названии локусов HLA идентифицируют типы аллельных вариаций, которые указываются в следующем порядке: основные варианты, коррелирующие с серотипами HLA; все другие кодирующие вариации; синонимичные замены нуклеотидов в кодирующих областях; некодирующие различия, включая полиморфизмы промоторов.

Белки - продукты экспрессии генов HLA-A, HLA-B и HLA-C представляют собой классические тяжелые $\alpha$-цепи класса I человеческих лейкоцитарных антигенов (HLA), которые после соединения инвариантной легкой цепью $\beta-2$ микроглобулина образуют иммуноглобулиновый домен, содержащий пептидсвязывающую канавку $[11,15]$. Молекула белка HLA ॥ класса образуется соединением $\alpha$ - и $\beta$-цепей, каждая из которых несет один иммуноглобулиновый домен [15]. Согласно номенклатуре варианты белка, кодируемые генами $H L A$, обычно указываются без промежуточных звездочек и двоеточий, например, следует указывать, что ген $H L A-B^{\star} 27: 05$ кодирует тяжелую цепь белка HLA-B2705.

Молекулы HLA класса I в основном презентируют пептиды, образующиеся в цитоплазме, цитотоксическим CD8+ Т-лимфоцитам [16]. Молекулы HLA класса II связывают пептиды, полученные в результате расщепления белка, обычно попавшего в клетку из внеклеточной среды, и презентируют их CD4+ Т-лимфоцитам, которые после этого начинают продуцировать цитокины, активирующие другие клетки, участвующие в развитии иммунной реакции.

\section{Роль генов HLA у больных псориазом и псориатическим артритом}

Распознавание HLA-связанных пептидов с помощью Т-клеточных рецепторов стимулирует тимическую селекцию и другие механизмы иммунной толерантности. Однако гены и белки HLA не только играют функциональную роль, но и могут участвовать в патогенезе различных заболеваний, способствуя развитию реакций на собственные белки.

С целью выявления аллелей генов HLA, способствующих развитию псориатического артрита у больных псориазом, нами проведен анализ литературных данных, в которых оценивалась частота носительства различных аллелей генов HLA у больных псориатическим артритом. Чтобы различать генетический риск, ассоциированный с предрасположенностью к псориатическому артриту, и риск, ассоциированный с развитием псориаза, учитывали варианты генов, носительство которых ассоциировано только с псориатическим артритом, но не с псориазом, или варианты генов, ассоциация которых с артритом значительно более выражена в сравнении с псориазом.

\section{Роль HLA-B`27}

Примером наиболее сильной ассоциативной связи с предрасположенностью к развитию псориатического артрита является аллельный вариант 27 локуса HLA-B. Повышение частоты носительства $H L A-B^{\star} 27$ у больных псориатическим артритом по сравнению с общей популяцией обнаружено в Великобритании, Испании, в ирландской популяции и среди этнических китайцев (ханьская этническая принадлежность) (табл. 1) [1720]. В России также была обнаружена высокая частота встречаемости $H L A-B^{\star} 27$ у больных псориатическим артритом, однако этническая принадлежность больных не была охарактеризована [21]. Значение этнической характеристики обследованных больных подчеркивается результатами исследования, проведенного в Израиле среди евреев ашкеназов и сефардов и не обнаружившего ассоциации псориатического артрита и $H L A-B^{\star} 27$ [22]. Авторы объяснили полученные результаты низкой частотой встречаемости $H L A-B^{\star} 27$ в Израиле, однако следует также учитывать малый размер выборки в этом исследовании - 50 больных псориатическим артритом, которые к тому же далее подразделялись на группы ашкеназов и сефрардов [22]. 
Таблица 1. Результаты оценки частоты встречаемости аллеля HLA-B*27 у больных псориатическим артритом в различных странах

Table 1. The frequency of the $H L A-B^{*} 27$ allele occurrence in patients with psoriatic arthritis in various countries

\begin{tabular}{ccccc}
\hline Страна & $\begin{array}{c}\text { Частота HLA-B*27 у больных } \\
\text { псориатическим артритом, } \%\end{array}$ & $\begin{array}{c}\text { Популяционная частота } \\
\text { HLA-B*27, } \%\end{array}$ & $\begin{array}{c}\text { Отношение } \\
\text { шансов }\end{array}$ & Ссылка \\
\hline Великобритания & 20 & 9,5 & Нет данных & $\begin{array}{c}\text { Williamson L., Dockerty J.L., } \\
\text { Dalbeth N. et al., 2004 }\end{array}$ \\
\hline Испания & 22,1 & 3,7 & 7,4 & $\begin{array}{c}\text { Lopez-Larrea C., Torre Alonso J.C., } \\
\text { Rodriguez Perez A., Coto E., 1990 }\end{array}$ \\
\hline Тайвань & 25,27 & 5,33 & 6,01 & $\begin{array}{r}\text { Liao H.T., Lin K.C., Chang Y.T. et al., } \\
\text { 2008 }\end{array}$ \\
\hline Россия & 20,2 & 7,3 & 3,20 & $\begin{array}{r}\text { Бадокин B.B., Tpowкина И.A., } \\
\text { Гyceва И.A., 2012 }\end{array}$ \\
\hline Ирландия & 15,6 & 5,5 & 3,18 & $\begin{array}{c}\text { Winchester R., Minevich G., } \\
\text { Steshenko V. et al., 2012 }\end{array}$ \\
\hline
\end{tabular}

Исследование, проведенное в Ирландии, показало, что в группе больных псориатическим артритом, представлявших гомогенную популяцию, частота носительства аллеля $H L A-B^{\star} 27$ ( $\left.B^{\star} 27: 05: 02\right)$, составившая $15,6 \%$, значительно превышала ее в группе больных псориазом - 4,7\% (отношение шансов - 3,77) [20]. В Китае частота носительства $H L A-B^{\star} 27$ среди больных псориатическим артритом - 25,27\% была значительно выше, чем среди больных псориазом - 5,0\% (отношение шансов - 6,42) [19]. В группе ирландских больных псориатическим артритом была также отмечена более высокая частота носительства гаплотипов EH27.1 $\left(B^{\star} 27-C^{\star} 01\right)-8,1 \%$ по сравнению с 1,9\% носителей среди больных псориазом (отношение шансов - 4,61) и EH27.2 (B*27-C*02) - 7\% по сравнению с 2,8\% носителей в группе больных псориазом (отношение шансов - 2,59) [20]. Поскольку гаплотипы EH27.1 и EH27.2 включают один и тот же аллель $B^{\star} 27$, но различаются по своим аллелям локуса $H L A-C$, считается, что эта предрасположенность определяется локусом $H L A-B$ [20].

Показано также, что аллель $H L A-B^{\star} 27$ определяет предрасположенность к развитию отдельных фрорм псориатического артрита (табл. 2). С ним связывают развитие аксиального псориатического артрита [23-25]. Однако в других исследованиях эти данные не были подтверждены $[17,26]$. Поэтому предполагается, что невыявление ассоциации $H L A-B^{\star} 27$ и развития псориатического артрита было обусловлено тем, что развитию аксиального псориатического артрита способствуют только отдельные варианты аллеля $H L A-B^{\star} 27$. Например, было обнаружено, что развитие симметричного сакроилеита ассоциировано с носительством $B^{\star}$ 27:05:02 $[27,28]$. Кроме того, носительство аллеля $B^{\star}$ 27:05:02 ассоциировано с риском развития дактилита, энтезита, остеолиза и эрозий суставов [18, 21, 23, 29, 30].

\section{HLA-B39 и -B38}

У пациентов с псориатическим артритом обнаружена повышенная частота встречаемости HLA-B39 [31-33]. Серологическая группа аллелей В39 содержит 57 подтипов аллелей, которые различаются своими кодирующими областями. Предрасположенность к развитию псориатического артрита связывают с носительством аллеля $B^{\star}$ 39:01:01:01 ( $\left.B^{\star} 39: 01\right)$, который значительно чаще обнаруживался при псориатическом артрите - у 6,4\% больных по сравнению с псориазом у 2,3\% больных (отношение шансов - 2,86) [20]. Этот аллель находится в неравновесном сцеплении с локусом $C^{\star}$ 12:03:01:01 ( $\left.C^{\star} 12\right)$, составляя с ним гаплотип EH39.1 (B*39:01-C*12). Гаплотип ЕН39.1 также ассоциируется С предрасположенностью к развитию псориатического артрита. Он был выявлен у 5,3\% больных псориатическим артритом и только у 1,4\% больных псориазом (отношение шансов - 3,93) [20].

Отмечено повышение частоты встречаемости у канадских больных псориатическим артритом аллеля HLA-B38, выявленного у 35,7\% пациентов с поражением суставов, ни у одного больного псориазом и у $6,9 \%$ здоровых лиц [34]. Позднее исследователями в США этот аллель был выявлен у 23,07\% пациентов с псориатическим артритом, тогда как у пациентов с псориазом он обнаружен только в $6,83 \%$ случаев, а у здоровых лиц - в 3,97\% случаев [35]. В Российской Федерации также обнаружена повышенная частота носительства среди больных псориатическим артритом - 23,2\% по сравнению со здоровым контролем 4,7\% (отношение шансов - 6,18) [21]. Кроме того, в России была выявлена ассоциация $H L A-B 38$ с развитием псориатического полиартрита (отношение шансов - 5,90) и артрита дистальных межфаланговых суставов (отношение шансов - 4,54) [21]. Однако в последующем не было подтверждено, что HLA-B38 является фрактором, предрасполагающим к развитию псориатического артрита [31]. Не было выявлено различий в частоте встречаемости у больных псориатическим артритом и больных псориазом аллеля $B^{\star} 38: 01: 01$ и гаплотипа $E H 38.1\left(B^{\star} 38-C^{\star} 12\right)$ в ирландской популяции [20].

Гаплотип ЕН38.1, как и предрасполагающий к развитию псориатического артрита гаплотип ЕН39.1, включает аллель $C^{\star} 12$, но при этом другой белок гаплотипа $E H 38.1-B^{\star} 38: 01: 01$ отличается от белка $B^{\star}$ 39:01 своим аминокислотным составом и, соответственно, электрическим зарядом этих аминокислот, в связи с чем предполагается, что эти молекулы связываются преимущественно с разными пептидами [27]. Считается, что если гаплотип ЕН38.1 и является предрасполагающим к развитию псориатического артрита, то вклад его более слабый по сравнению с вкладом $B^{\star}$ 39:01. Возможно также, что влияние гаплотипа ЕН38.1 на заболеваемость псориатическим артритом трудно выявить из-за значительных различий частоты его встречаемости внутри подгрупп европейской популяции [20]. 
Таблица 2. Ассоциация носительства гена HLA-B 27 и гаплотипов, его включающих, с различными признаками псориатического артрита

Table 2. Association of the carriage of the HLA-B*27 gene and it's haplotypes with various signs of psoriatic arthritis

\begin{tabular}{|c|c|c|c|c|c|}
\hline \multirow{2}{*}{$\begin{array}{l}\text { Аллель/ } \\
\text { гаплотип }\end{array}$} & \multirow{2}{*}{$\begin{array}{l}\text { Клинический } \\
\text { признак }\end{array}$} & \multicolumn{2}{|c|}{ Частота встречаемости, \% } & \multirow{2}{*}{$\begin{array}{l}\text { Отношение } \\
\text { шансов }\end{array}$} & \multirow[b]{2}{*}{ Ссылка } \\
\hline & & $\begin{array}{l}\text { у больных } \\
\text { с признаком }\end{array}$ & $\begin{array}{c}\text { у больных } \\
\text { без признака }\end{array}$ & & \\
\hline$H L A-B^{\star} 27$ & $\begin{array}{c}\text { Аксиальный } \\
\text { псориатический } \\
\text { артрит }\end{array}$ & 30 & 10 & 5,75 & $\begin{array}{l}\text { Chandran V., Tolusso D.C., } \\
\text { Cook R.J., Gladman D.D., } 2010\end{array}$ \\
\hline$H L A-B^{\star} 27$ & Спондилоартрит & Нет данных & Нет данных & 6,32 & $\begin{array}{c}\text { Бадокин В.В., Трошкина И.А., } \\
\text { Гусева И.А., } 2012\end{array}$ \\
\hline$H L A-B^{\star} 27$ & Спондилоартрит & 54 & Нет данных & 38,8 & $\begin{array}{l}\text { Lopez-Larrea C., Torre Alonso J.C., } \\
\text { Rodriguez Perez A., Coto E., } 1990\end{array}$ \\
\hline$H L A-B^{\star} 27 / C W^{*} 1$ & Спондилоартрит & 11 & Нет данных & 13,8 & $\begin{array}{l}\text { Lopez-Larrea C., Torre Alonso J.C., } \\
\text { Rodriguez Perez A., Coto E., } 1990\end{array}$ \\
\hline$H L A-B^{\star} 27$ & Полиартрит & Нет данных & Нет данных & 3,26 & $\begin{array}{c}\text { Бадокин В.В., Трошкина И.А., } \\
\text { Гусева И.А., } 2012\end{array}$ \\
\hline$H L A-B^{\star} 27: 05: 02$ & $\begin{array}{l}\text { Симметричный } \\
\text { сакроилеит }\end{array}$ & 61,1 & 12,9 & 10,6 & $\begin{array}{l}\text { Haroon M., Winchester R., } \\
\text { Giles J.T. et al., } 2016\end{array}$ \\
\hline$H L A-B^{\star} 27: 05: 02$ & $\begin{array}{l}\text { Симметричный } \\
\text { сакроилеит }\end{array}$ & 61 & $10 \dagger$ & Нет данных & $\begin{array}{l}\text { Haroon M., Winchester R., } \\
\text { Giles J.T. et al., } 2017\end{array}$ \\
\hline $\begin{array}{l}B^{\star} 27: 05: 02- \\
C^{*} 02: 02: 02\end{array}$ & $\begin{array}{c}\text { Симметричный } \\
\text { сакроилеит }\end{array}$ & 26,3 & 5,3 & 6,3 & $\begin{array}{l}\text { Haroon M., Winchester R., } \\
\text { Giles J.T. et al., } 2016\end{array}$ \\
\hline $\begin{array}{l}B^{\star} 27: 05: 02- \\
C^{*} 01: 02: 01\end{array}$ & $\begin{array}{l}\text { Симметричный } \\
\text { сакроилеит }\end{array}$ & 31,6 & 7,2 & 6,0 & $\begin{array}{l}\text { Haroon M., Winchester R., } \\
\text { Giles J.T. et al., } 2016\end{array}$ \\
\hline$B^{\star} 27: 05: 02$ & Дактилит & 21,3 & 9,8 & 2,5 & $\begin{array}{l}\text { Haroon M., Winchester R., } \\
\text { Giles J.T. et al., } 2016\end{array}$ \\
\hline $\begin{array}{l}B^{*} 27: 05: 02- \\
C^{*} 01: 02: 01\end{array}$ & Дактилит & 12,0 & 5,3 & 2,5 & $\begin{array}{l}\text { Haroon M., Winchester R., } \\
\text { Giles J.T. et al., } 2016\end{array}$ \\
\hline$B * 27: 05: 02$ & Энтезит & 28,1 & 9,7 & 3,7 & $\begin{array}{l}\text { Haroon M., Winchester R., } \\
\text { Giles J.T. et al., } 2016\end{array}$ \\
\hline $\begin{array}{l}B^{*} 27: 05: 02- \\
C^{*} 01: 02: 01\end{array}$ & Энтезит & 17,5 & 4,3 & 4,7 & $\begin{array}{l}\text { Haroon M., Winchester R., } \\
\text { Giles J.T. et al., } 2016\end{array}$ \\
\hline$H L A-B^{\star} 27$ & $\begin{array}{l}\text { Степень тяжести } \\
\text { энтезита }\end{array}$ & Нет данных & Нет данных & Нет данных & $\begin{array}{l}\text { Polachek A., Cook R., } \\
\text { Chandran V. et al., } 2018\end{array}$ \\
\hline $\begin{array}{l}B^{\star} 27: 05: 02- \\
C^{\star} 01: 02: 01\end{array}$ & $\begin{array}{c}\text { Остеолиз и эрозии } \\
\text { суставов }\end{array}$ & 64 & 13,0 & 5,7 & $\begin{array}{l}\text { Haroon M., Winchester R., } \\
\text { Giles J.T. et al., } 2016\end{array}$ \\
\hline
\end{tabular}

Примечание: $†$ - частота носительства $H L A-B^{\star}$ 27:05:02 у больных с асимметричным сакроилеитом.

Note: $\dagger-$ frequency of carriage of $H L A-B^{\star} 27: 05: 02$ in patients with asymmetric sacroilitis.

R. Winchester и соавт. (2016) обнаружили ассоциацию носительства аллеля $B^{\star}$ 38:01:01 с развитием асимметричного, но не с развитием симметричного сакроилеита, что позволяет говорить о различных механизмах развития этих патологических состояний [27]. Поэтому противоречивость результатов исследований ассоциации HLA-B38 с развитием псориатического артрита может быть обусловлена также и тем, что его носительство способствует развитию лишь определенных клинических форм болезни.

\section{HLA-B*08:01 и другие}

Имеются данные, что развитию псориатического артрита может способствовать аллель $B^{\star} 08: 01$. Обнаружено, что носителями $H L A-B^{\star} 08$ ( $\left.B^{\star} 08: 01\right)$ являются $37,3 \%$ больных псориатическим артритом, что значительно больше, чем больных псориазом $(24,8 \%)$ (отношение шансов - 1,81). Также у больных псориатическим артритом значительно чаще выявлялся гаплотип EH8.1 ( $\left.B^{\star} 08: 01-C^{\star} 07\right)$ - в 36,8\% случаев, чем у больных псориазом - в 24,3\% случаев (отношение шансов 1,81 ] [20]. Выявлено, что аллель $B^{\star}$ 08:01:01 является фактором, предрасполагающим к развитию отдельных клинических форм псориатического артрита - асимметричного сакроилеита, дактилита, энтезита, анкилозов и деформаций суставов (табл. 3).

В формировании предрасположенности к развитию отдельных фоорм псориатического артрита может также участвовать ген $H L A-B^{\star} 55: 01: 01$. Имеются данные, что его носительство предрасполагает к развитию асимметричного сакроилеита и энтезита [27].

В испанской популяции выявлена повышенная частота встречаемости аллеля $H L A-B^{\star} 17$ у больных псориатическим артритом - в 19,2\% случаев по сравнению со здоровыми лицами - в 4,6\% случаев (отношение шансов - 4,9) [18]. Этот аллель $H L A-B^{\star} 17$ был ассоциирован в испанской популяции с развитием спондилоартрита (отношение шансов - 6,6) и олигоартрита (отношение шансов - 5,9) [18].

Получены данные о влиянии на предрасположенность к развитию псориатического артрита аллеля $H L A-B^{\star} 18$ (B*18:01:01), который был выявлен у 5,8\% больных псориатическим артритом и у $0,9 \%$ больных псориазом (отношение шансов - 6,59) [20]. Кроме 
Таблица 3. Ассоциация носительства гена HLA-B*08 и гаплотипов, его содержащих, с различными клиническими признаками псориатического артрита

Table 3. Association of the carriage of the HLA-B*08 gene and it's haplotypes with various signs of psoriatic arthritis

\begin{tabular}{|c|c|c|c|c|c|}
\hline \multirow{2}{*}{$\begin{array}{l}\text { Аллель/ } \\
\text { гаплотип }\end{array}$} & \multirow{2}{*}{$\begin{array}{l}\text { Клинический } \\
\text { признак }\end{array}$} & \multicolumn{2}{|c|}{ Частота встречаемости, \% } & \multirow{2}{*}{$\begin{array}{l}\text { Отношение } \\
\text { шансов }\end{array}$} & \multirow[b]{2}{*}{ Ссылка } \\
\hline & & $\begin{array}{l}\text { у больных } \\
\text { с признаком }\end{array}$ & $\begin{array}{c}\text { у больных } \\
\text { без признака }\end{array}$ & & \\
\hline$B^{*} 08: 01$ & Сакроилеит с эрозиями & 50 & 33 & 2,76 & $\begin{array}{l}\text { Haroon M., Winchester R., } \\
\text { Giles J.T. et al., } 2017\end{array}$ \\
\hline$B^{*} 08: 01: 01$ & $\begin{array}{l}\text { Асимметричный } \\
\text { сакроилеит }\end{array}$ & 62,7 & 31,2 & 3,7 & $\begin{array}{l}\text { Haroon M., Winchester R., } \\
\text { Giles J.T. et al., } 2016\end{array}$ \\
\hline $\begin{array}{l}B^{*} 08: 01: 01- \\
C^{*} 07: 01: 01\end{array}$ & $\begin{array}{l}\text { Асимметричный } \\
\text { сакроилеит }\end{array}$ & 58,4 & 31 & 3,1 & $\begin{array}{l}\text { Haroon M., Winchester R., } \\
\text { Giles J.T. et al., 2017; } \\
\text { Winchester R., Giles J., } \\
\text { Jadon D. et al., } 2016\end{array}$ \\
\hline$B^{*} 08: 01: 01$ & Дактилит & 42,7 & 30,3 & 1,7 & $\begin{array}{l}\text { Haroon M., Winchester R., } \\
\text { Giles J.T. et al., } 2016\end{array}$ \\
\hline $\begin{array}{l}B^{*} 08: 01: 01- \\
C^{*} 07: 01: 01\end{array}$ & Дактилит & 42,0 & 29,3 & 1,8 & $\begin{array}{l}\text { Haroon M., Winchester R., } \\
\text { Giles J.T. et al., 2016 }\end{array}$ \\
\hline$B^{\star} 08: 01: 01$ & Анкилозы суставов & 48,8 & 32,0 & 2 & $\begin{array}{l}\text { Haroon M., Winchester R., } \\
\text { Giles J.T. et al., } 2016\end{array}$ \\
\hline$B^{\star} 08: 01: 01$ & Деформации суставов & 43,4 & 25,0 & 2,3 & $\begin{array}{l}\text { Haroon M., Winchester R., } \\
\text { Giles J.T. et al., } 2016\end{array}$ \\
\hline $\begin{array}{l}B^{\star} 08: 01: 01- \\
C^{*} 07: 01: 01\end{array}$ & Деформации суставов & 42,1 & 25,0 & 2 & $\begin{array}{l}\text { Haroon M., Winchester R., } \\
\text { Giles J.T. et al., } 2016\end{array}$ \\
\hline
\end{tabular}

того, носительство гена $H L A-B^{\star} 18: 01: 01$ может способствовать развитию энтезита [27].

В Российской Федерации была обнаружена повышенная частота носительства $H L A-B^{\star} 13$ у больных псориатическим артритом - 23,2\% по сравнению со здоровыми лицами - 10,0\% (отношение шансов - 2,72) [21]. В испанской популяции также выявлена ассоциация $H L A-B^{\star} 13$ с развитием олигоартрита (отношение шанCOB - 4,6) [18].

Вклад в развитие различных форм псориатического артрита могут вносить не только ген $H L A-B$, но и различные аллели локуса $H L A-C$. В китайской популяции выявлено преобладание носительства $H L A-C w^{\star} 12$ среди больных псориатическим артритом - 24,18\% по сравнению со здоровым контролем - 3,75\% (отношение шансов - 8,18) [19]. Важную роль в формировании предрасположенности к развитию различных форм псориатического артрита могут играть $H L A-C^{\star} 01, H L A-C^{\star} 02$, $H L A-C^{*} 05, H L A-C^{*} 07$ (табл. 4). Данные о значении аллеля $C^{\star}$ 01:02:01 как фрактора, предрасполагающего к развитию различных форм псориатического поражения суставов, подтверждаются более частым выявлением этого аллеля у пациентов с симметричным сакроилеитом, энтезитом, эрозивным поражением суставов. Показано

Таблица 4. Ассоциация носительства аллелей гена HLA-C с различными клиническими признаками псориатического артрита [29]

Table 4. Association of HLA-C allele carriage with various clinical signs of psoriatic arthritis [29]

\begin{tabular}{|c|c|c|c|c|}
\hline \multirow{2}{*}{ Аллель } & \multirow{2}{*}{ Клинический признак } & \multicolumn{2}{|c|}{ Частота встречаемости, \% } & \multirow{2}{*}{ Отношение шансов } \\
\hline & & у больных с признаком & у больных без признака & \\
\hline$C^{*} 01: 02: 01$ & $\begin{array}{c}\text { Симметричный } \\
\text { сакроилеит }\end{array}$ & 36,8 & 9,5 & 5,6 \\
\hline$C^{*} 01: 02: 01$ & Энтезит & 21,6 & 5,9 & 4,4 \\
\hline$C^{*} 01: 02: 01$ & $\begin{array}{c}\text { Остеолиз и эрозии } \\
\text { суставов }\end{array}$ & 16,3 & 7,0 & 2,6 \\
\hline$C^{\star} 02: 02: 02$ & $\begin{array}{l}\text { Симметричный } \\
\text { сакроилеит }\end{array}$ & 26,3 & 6,4 & 5,1 \\
\hline$C^{*} 02: 02: 02$ & Дактилит & 10,7 & 4,5 & 2,5 \\
\hline$C^{*} 02: 02: 02$ & $\begin{array}{c}\text { Остеолиз и эрозии } \\
\text { суставов }\end{array}$ & 17,1 & 6,3 & 3,1 \\
\hline$C^{\star} 05: 01: 01$ & $\begin{array}{c}\text { Асимметричный } \\
\text { сакроилеит }\end{array}$ & 25,5 & 14,2 & 2,1 \\
\hline$C^{\star} 07: 01: 01$ & Дактилит & 48,7 & 31,6 & 2 \\
\hline$C^{*} 07: 01: 01$ & Анкилозы суставов & 53 & 35,5 & 2 \\
\hline$C^{\star} 07: 01: 01$ & Десоормации суставов & 46,4 & 30,0 & 2 \\
\hline
\end{tabular}


значение $C^{\star}$ 02:02:02 в развитии симметричного сакроилеита, дактилита, эрозий суставов. Аллель $C^{\star}$ 05:01:01 оказался фрактором, предрасполагающим к развитию асимметричного сакроилеита. С носительством аллеля $C^{\star}$ 07:01:01 ассоциируется развитие у пациентов с псориатическим артритом дактилита, анкилозов и деформаций суставов [29].

В Израиле получены данные об ассоциации вариантов HLA-A и HLA класса II, хотя обследованная выборка была небольшой [22]. Обнаружена ассоциация HLA$D R B^{\star}$ 01:01, -DRB*03:01 и -DRB-04:03 с развитием псориатического артрита. Носительство HLA-A*3 было ассоциировано с развитием артрита дистальных межфраланговых суставов, $H L A-D R B^{\star} 03: 01-c$ аксиальным воспалительным поражением [22].

\section{Аллели $H L A$, ассоциированные с низкой частотой развития псориатического артрита}

Обнаружены аллели $H L A$, встречающиеся у пациентов с псориатическим артритом или его отдельными формами реже, чем у пациентов без этого заболевания. Такие аллели рассматриваются как защитные, то есть препятствующие развитию псориатического артрита и его определенных форм. Как протективный в отношении развития псориатического артрита рассматривается аллель $C^{\star} 06$ ( $\left.C^{\star} 06: 02: 01: 01\right)$, выявленный у 28,7\% пациентов с псориатическим поражением суставов и у $57,5 \%$ больных псориазом (отношение шансов $0,30)$ [20]. Одним из аллелей с протективным эффректом является $B^{\star} 57: 01: 01$. В Ирландии аллель $B^{\star} 57$ ( $B^{\star}$ 57:01:01) встречался значительно реже у пациентов с псориатическим артритом - в 18,4\% случаев, чем у пациентов с псориазом - в 31,8\% случаев (отношение шансов - 0,48) [20]. Обнаружено, что $B^{\star}$ 57:01:01, а также гаплотип $B^{\star}$ 57:01:01- $C^{\star}$ 06:02:01 значительно реже встречались у пациентов с асимметричным сакроилеитом (в 15,8\% случаев) по сравнению с больными без асимметричного сакроилеита, у которых $B^{\star}$ 57:01:01 был выявлен в 37,5\% случаев (отношение шансов $0,31)$ [29]. В Китае как протективный рассматривается аллель $B^{\star} 58$, который был выявлен у 6,60\% больных псориатическим артритом и у 26,67\% здоровых лиц (отношение шансов - 0,19) [19].

В испанской популяции среди больных псориатическим артритом значительно меньше частота носительства аллеля $H L A-B^{\star} 44-$ у $14,4 \%$ больных по сравнению со здоровым контролем - в 29,4\% случаев (отношение шансов - 0,4), что указывает на наличие у него протективного эфффекта [18]. Частота встречаемости аллеля $B^{\star} 44$ ( $\left.B^{\star} 44: 02: 01: 01\right)$ в ирландской популяции также значительно ниже у пациентов с псориатическим артритом, у которых он был выявлен в 14\% случаев, по сравнению с больными псориазом, у которых он был выявлен в 22,8\% случаев (отношение шансов - 0,60) [20]. Получены также данные, что аллель $B^{\star} 44: 02: 01$ является протективным в отношении развития дактилита, развития неподвижности суставов, а также остеолиза или эрозивного поражения суставов (табл. 5). Отмечен также защитный эффрект аллеля $B^{\star} 44: 03: 01$ в отношении развития дактилита, неподвижности и деформации суставов [29].

В российской популяции выявлен защитный эфффект аллеля $B^{\star} 07$ в отношении развития псориатического олигоартрита [21]. Получены данные о защитном эффекте аллеля $C^{*} 16: 01: 01$ в отношении развития дактилита, анкилозов и десрормации суставов [29]. Кроме того, аллель $C^{*}$ 06:02:01 может оказывать протективный эффект в отношении развития дактилита и симметричного сакроилеита [27].

Результаты исследования в китайской популяции позволяют предполагать существование протективного эфффекта у одного из генов HLA II класса - HLA-DR*07. Носителями $H L A-D R^{\star} 07$ среди этнических китайцев были 4,40\% пациентов с псориатическим артритом, что значительно меньше числа его носителей среди больных псориазом - 27,50\% (отношение шансов $0,12)[19]$.

\section{Обсуждение}

Результаты анализа литературы демонстрируют ассоциацию аллелей генов HLA с предрасположенностью к развитию псориатического артрита у больных псориазом.

Наиболее выражена связь с развитием псориатического поражения суставов у аллелей генов HLA класса I, в первую очередь локуса $H L A-B$, среди которых важное значение имеют аллели $H L A-B^{\star} 27, H L A-B^{\star} 39, H L A-B^{\star} 38$, $H L A-B^{\star} 08, H L A-B^{\star} 17, H L A-B^{\star} 18, H L A-B^{\star} 13$, хотя аллели локуса $H L A-C$ также могут ассоциироваться с псориатическим артритом (HLA-C*01, HLA-C*02, HLA-C*05, $\left.H L A-C^{\star} 07, H L A-C w^{\star} 12\right)$. В отдельных исследованиях показано существование ассоциации между псориатическим артритом и аллелями генов $H L A$ класса II - HLA$D R B^{\star} 01: 01,-D R B^{\star} 03: 01$ и -DRB-04:03.

Полученные данные предполагают также существование ассоциации некоторых аллелей генов HLA с определенными формами псориатического артрита - аксиальным артритом, дактилитом, энтезитом. Выявлено также, что эффект носительства аллелей генов HLA, ассоциированных с псориатическим артритом, может иметь разную направленность. Описаны аллели генов $H L A$, как увеличивающие вероятность развития псориатического артрита, так и аллели с протективным эффектом, наличие которых уменьшает вероятность развития псориатического поражения суставов - HLA-B*57:01:01, $H L A-B^{\star} 44$ (B*44:02:01:01), HLA-B*44:03:01.

Различия в направленности и выраженности эффекта аллелей генов $H L A$ в определении предрасположенности к развитию псориатического артрита обусловлены чрезвычайной вариабельностью белков, которые они кодируют. Свои функции белки HLA классов I и II осуществляют за счет наличия в их структуре пептидсвязывающей канавки, свойства которой определяются в первую очередь составом аминокислотных остатков, принимающих участие в ее формировании. В молекулах белков HLA класса I связывающая канавка по краям прикрывается консервативными остатками тирозина, что приводит к ограничению размера связываемых пептидов. Обычно пептидсвязывающую канавку белков HLA I класса занимают пептиды, содержащие 8-12 аминокислотных остатков, в большинстве случаев - 9 остатков [36-41].

Широкий спектр аллельных вариантов полиморфризма генов HLA I и II классов отражается в вариабельности белков HLA, которые они кодируют. Аллельное разнообразие в основном влияет на форму, распределение заряда и аминокислотный состав пептидсвязывающей канавки, что в свою очередь влияет на изменение функций белков HLA. Замена даже одной аминокислоты в составе канавки может привести 
Таблица 5. Аллели и гаплотипы генов системы HLA, обладающие протективным эффеектом в отношении развития псориатического артрита, с учетом его клинических признаков

Table 5. Alleles and haplotypes of genes of the HLA system with protective effect against the development of psoriatic arthritis and clinical signs of psoriatic arthritis

\begin{tabular}{|c|c|c|c|c|c|}
\hline \multirow{2}{*}{$\begin{array}{l}\text { Аллель/ } \\
\text { гаплотип }\end{array}$} & \multirow{2}{*}{$\begin{array}{l}\text { Клинический } \\
\text { признак }\end{array}$} & \multicolumn{2}{|c|}{ Частота встречаемости, \% } & \multirow{2}{*}{$\begin{array}{l}\text { Отношение } \\
\text { шансов }\end{array}$} & \multirow[b]{2}{*}{ Ссылка } \\
\hline & & $\begin{array}{c}\text { у больных } \\
\text { с признаком }\end{array}$ & $\begin{array}{c}\text { у больных } \\
\text { без признака }\end{array}$ & & \\
\hline$B^{\star 44: 02: 01}$ & Дактилит & 9,3 & 22,0 & 0,37 & $\begin{array}{l}\text { Haroon M., Winchester R., } \\
\text { Giles J.T. et al., } 2016\end{array}$ \\
\hline $\begin{array}{l}B^{*} 44: 02: 01- \\
C^{*} 05: 01: 01\end{array}$ & Дактилит & 8,7 & 18,0 & 0,43 & $\begin{array}{l}\text { Haroon M., Winchester R., } \\
\text { Giles J.T. et al., } 2016\end{array}$ \\
\hline$B^{\star 44: 02: 01}$ & Анкилоз суставов & 4,9 & 19,5 & 0,21 & $\begin{array}{l}\text { Haroon M., Winchester R., } \\
\text { Giles J.T. et al., 2016; }\end{array}$ \\
\hline $\begin{array}{l}B^{*} 44: 02: 01- \\
C^{*} 05: 01: 01\end{array}$ & Анкилоз суставов & 4,8 & 16,5 & 0,26 & $\begin{array}{l}\text { Haroon M., Winchester R., } \\
\text { Giles J.T. et al., } 2016\end{array}$ \\
\hline$B^{\star} 44: 02: 01$ & $\begin{array}{c}\text { Остеолиз и эрозии } \\
\text { суставов }\end{array}$ & 10,7 & 19,0 & 0,51 & $\begin{array}{l}\text { Haroon M., Winchester R., } \\
\text { Giles J.T. et al., } 2016\end{array}$ \\
\hline $\begin{array}{l}B^{*} 44: 02: 01- \\
C^{*} 05: 01: 01\end{array}$ & $\begin{array}{c}\text { Остеолиз и эрозии } \\
\text { суставов }\end{array}$ & 8,9 & 16,5 & 0,5 & $\begin{array}{l}\text { Haroon M., Winchester R., } \\
\text { Giles J.T. et al., } 2016\end{array}$ \\
\hline$B^{\star 44: 03: 01}$ & Дактилит & 6,0 & 15,2 & 0,36 & $\begin{array}{l}\text { Haroon M., Winchester R., } \\
\text { Giles J.T. et al., } 2016\end{array}$ \\
\hline $\begin{array}{l}B^{*} 44: 03: 01- \\
C^{*} 16: 01: 01\end{array}$ & Дактилит & 3,3 & 9,8 & 0,3 & $\begin{array}{l}\text { Haroon M., Winchester R., } \\
\text { Giles J.T. et al., } 2016\end{array}$ \\
\hline$B^{*} 44: 03: 01$ & Анкилоз суставов & 3,7 & 13,0 & 0,25 & $\begin{array}{l}\text { Haroon M., Winchester R., } \\
\text { Giles J.T. et al., } 2016\end{array}$ \\
\hline $\begin{array}{l}B^{*} 44: 03: 01- \\
C^{*} 16: 01: 01\end{array}$ & Анкилозы суставов & 1,2 & 8,5 & 0,13 & $\begin{array}{l}\text { Haroon M., Winchester R., } \\
\text { Giles J.T. et al., } 2016\end{array}$ \\
\hline$B^{*} 44: 03: 01$ & Деформации суставов & 7,1 & 16,0 & 0,41 & $\begin{array}{l}\text { Haroon M., Winchester R., } \\
\text { Giles J.T. et al., } 2016\end{array}$ \\
\hline $\begin{array}{l}B^{*} 44: 03: 01- \\
C^{*} 16: 01: 01\end{array}$ & Деформации суставов & 3,3 & 12,0 & 0,24 & $\begin{array}{l}\text { Haroon M., Winchester R., } \\
\text { Giles J.T. et al., } 2016\end{array}$ \\
\hline$C^{*} 16: 01: 01$ & Дактилит & 4,0 & 9,8 & 0,4 & $\begin{array}{l}\text { Haroon M., Winchester R., } \\
\text { Giles J.T. et al., } 2016\end{array}$ \\
\hline$C^{*} 16: 01: 01$ & Анкилозы суставов & 2,4 & 8,5 & 0,3 & $\begin{array}{l}\text { Haroon M., Winchester R., } \\
\text { Giles J.T. et al., } 2016\end{array}$ \\
\hline$C^{*} 16: 01: 01$ & Деформации суставов & 3,8 & 12,0 & 0,29 & $\begin{array}{l}\text { Haroon M., Winchester R., } \\
\text { Giles J.T. et al., } 2016\end{array}$ \\
\hline
\end{tabular}

к значительному изменению сродства к отдельным пептидам и, соответственно, репертуара презентируемых антигенных пептидов [42].

Примером являются различные варианты HLA$B^{\star} 27$ и HLA-B*39. Так, белки - продукты аллеля $B^{\star}$ 39:01, ассоциированного с развитием псориатического артрита, и $B^{\star}$ 39:06, ассоциация которого с псориатическим артритом не выявлена, В3901 и В3906 соответственно характеризуются лишь двумя различиями в аминокислотном составе - L95W и R97T. Предполагается, что эти различия влияют на функционирование связывающих карманов молекулы $H L A-B^{\star} 39$ [20, 42]. Всего одним аминокислотным остатком в положении 116 внутри пептидсвязывающей канавки различаются белки HLA-B`2705 и HLA-B*2709 (Asp-116 в молекуле $B^{\star} 2705$ и His-116 в молекуле $\left.B^{\star} 2709\right)$, но при этом аллель $H L A-B^{\star} 27: 05$ ассоциирован с развитием воспалительных поражений суставов, а ассоциация аллеля $H L A-B^{\star} 27: 09$ с их развитием значительно менее выражена [43-48].

Ассоциация развития воспалительных заболеваний суставов, в том числе псориатического артрита, с носительством HLA-B27 является наиболее значимой и наиболее изученной. В настоящее время известно несколько гипотез, в которых рассматривается патогенетическая роль $H L A-B 27$ в развитии воспалительных заболеваний суставов [8].

Согласно гипотезе артритогенных пептидов, возможной причиной воспалительной реакции, вызванной HLA-B27, является презентация патогенных артритогенных пептидов (то есть экзогенных пептидов, которые достаточно похожи на собственные антигены, чтобы вызвать аутоиммунную реакцию) CD8+ Т-лимфоцитам, в результате чего происходит селекция высокоспецифичных аутореактивных Т-лимфоцитов [49].

Гипотеза открытых конфрормаций HLA-B27 на клеточной поверхности объясняет ассоциацию аллелей $H L A-B^{\star} 27$ с воспалительными заболеваниями суставов тем, что содержащийся в тяжелых цепях белка HLA-B27 цистеин (Cys67) (и, возможно, остатки цистеина в других положениях) способствует образованию незанятых антигенными пептидами открытых конфрормаций тяжелых цепей HLA-B27 (включая димеры и, возможно, другие формы), которые не образуют комплекс с $\beta 2$-микроглобулином [50]. Белки HLA-B27 с такими открытыми конформациями экспрессируются на поверхности клеток и участвуют в передаче патогенного сигнала [51-53]. 
Предложены также другие объяснения патогенетического значения $H L A-B^{\star} 27$ в развитии воспалительных заболеваний суставов, помимо канонической функции $H L A-B^{\star} 27$ как молекулы, презентирующей антигенный пептид цитотоксическим CD8+ Т-лимфроцитам. Существует также гипотеза, согласно которой причиной развития воспалительной реакции у носителей $H L A-B^{\star} 27$ являются неправильное свертывание полипептидной цепи белка HLA-B27, клеточная реакция на несвернутый белок в виде стресса эндоплазматического ретикулума и аутофрагия [54]. В данном случае патогенетическое значение имеют физико-химические характеристики молекулы белка HLA-B²7 [55]. Медленная сборка комплексов «антигенный пептид-HLA-B27» предрасполагает клетку к повышению уровня ассоциированной с эндоплазматическим ретикулумом деградации накапливающегося несвернутого белка, индукции реакции на несвернутый белок и аутофагии, особенно когда продукция HLA-B27 повышается во время воспаления [54]. Ассоциированные с заболеванием варианты HLA-B27 олигомеризуются, легче накапливаются в эндоплазматическом ретикулуме и более восприимчивы к деградации, чем не ассоциированные с заболеванием подтипы HLA-B27 [56-58].

Неправильное свертывание HLA-B27 в эндоплазматическом ретикулуме связывают с наличием в его составе аминокислотного остатка цистеина Суs67 и, как предполагается, с другими молекулярными свойствами тяжелых цепей HLA-B27 [54]. К замедлению свертывания и гомодимеризации полипептидной цепи белка HLA-B27 может также привести неправильное функционирование аминопептидаз эндоплазматического ретикулума и тапазина $[59,60]$. Неправильно свернутые белки в эндоплазматическом ретикулуме должны удаляться путем ассоциированной с эндоплазматическим ретикулумом деградации (ERAD). Неэфорективная внутриклеточная утилизация неправильно свернутых молекул белка HLA-B27 вызывает стресс эндоплазматического ретикулума, реакцию на несвернутый белок, что способствует выработке медиаторов воспаления [54, 61].

Вследствие более медленного сворачивания вновь синтезированной альфа-цепи $\mathrm{B}^{\star} 27$ в эндоплазматическом ретикулуме и запуска реакции на несвернутые белки, а также склонности молекулы HLA-B*27 к развертыванию на поверхности клетки с высвобождением альфа-цепей, которые могут быть распознаны представленным на естественных киллерах и Т-лимфоцитах рецептором KIR3DL2, носительство $H L A-B^{\star} 27$ ассоциируется с более интенсивной продукцией ИЛ-23 и активацией Th17-лимфоцитов [27]. В итоге происходит отбор клона Т-лимфоцитов, реагирующих на собственный пептид, презентируемый Т-лимфоцитам вариантом белка HLA-B*27, ассоциированным с развитием псориатического артрита, с последующей активацией и экспансией этого клона [27].

Кроме того, несмотря на консервативность мотива связывания антигенного пептида для каждого аллеля HLA в некоторых условиях, например, в воспалительной среде или при воздействии некоторых лекарственных препаратов при наличии определенных гаплотипов аминопептидаз эндоплазматического ретикулума ERAP1 и ERAP2, пептидсвязывающая канавка может принять конформацию, которая позволяет связывать нетрадиционные пептиды [59].

Поскольку ассоциацию $H L A-B^{\star} 27$ и псориатического артрита не всегда удавалось выявить, был необходим анализ частоты носительства различных вариантов этого аллеля у больных псориатическим артритом. Различные варианты белка HLA-B ${ }^{\star} 27$ отличаются аминокислотным составом, что приводит к их структурным различиям, имеющим особое значение, если они затрагивают пептид-связывающие карманы. Было показано, что развитию псориатического артрита наиболее способствует аллель $B^{\star}$ 27:05:02. Известно, что этот аллель отличается от других аллелей $B^{\star} 27$, не ассоциированных с заболеваниями суставов, структурными различиями пептид-связывающего кармана Р9, в результате чего у этих аллелей $B^{\star} 27$ различается состав преимущественно связываемых пептидов [27].

Проведенные исследования позволили оценить вероятность развития псориатического артрита у больных псориазом, которую рассчитывали как произведение отношения распространенности псориатического артрита к псориазу и соответствующих соотношений конкретных аллелей предрасположенности HLA в когортах больных псориатическим артритом и псориазом без артрита. На примере ирландской популяции было рассчитано, что наиболее высока вероятность развития псориатического артрита у больных псориазом при наличии $H L A-B^{\star} 27$. В таком случае развитие воспалительного поражения суставов ожидается в $33 \%$ случаев. При носительстве $H L A-B^{\star} 39: 01$ развитие псориатического артрита ожидается в $28 \%$ случаев, а при носительстве $H L A-C^{\star} 06$ - в 5\% случаев [20].

\section{Заключение}

K настоящему времени определены аллели генов HLA, ассоциированные с развитием псориатического артрита, при этом в исследованиях не выявлено, что эти аллели вносят значимый вклад в развитие псориатического поражения кожи. Механизм проявления патологического эффекта белков HLA, которые кодируются аллельными вариантами генов $H L A$, предрасполагающими к развитию псориатического артрита, состоит в том, что они презентируют Т-лимороцитам собственные пептиды организма человека или подобные им. Это формирует репертуар Т-лимсроцитов, которые приводят к аутоиммунному ответу, ориентированному на антигены, расположенные в тканях сустава [20].

Данные о вкладе генов $H L A$ в формирование предрасположенности к развитию псориатического артрита могут быть использованы для прогнозирования развития псориатического поражения суставов у больных псориазом. Известны также аллели генов HLA, носительство которых ассоциировано с определенными формами псориатического артрита - аксиальным артритом, дактилитом, энтезитом, развитием эрозивного поражения, анкилозов, деформаций суставов. В то же время ассоциация аллельных вариантов генов HLA с определенными формами псориатического артрита снижает вероятность ее выявления при обследовании больных псориатическим артритом без проведения анализа клинических характеристик болезни, что делает необходимой точную клиническую характеристику воспалительного поражения суставов. Имеющиеся данные о различной частоте встречаемости аллелей HLA в генетически различных популяциях требуют определения частоты носительства аллелей генов $H L A$, участвующих в формировании предрасположенности к развитию псориатического артрита, с учетом этнического происхождения изучаемой популяции. 
Следует также подчеркнуть, что псориатический артрит является полигенным заболеванием, и наличие аллелей предрасположенности к его развитию, локализующихся в геноме за пределами $H L A$, как правило, увеличивает вероятность развития заболевания по причине влияния определенных аллельных полиморфизмов генома [62, 63]. Стоит отметить, что наиболее точным методом прогнозирования развития псориатического артрита в настоящее время является применение критерия полигенного риска (polygenic risk score) [64].

\section{Литература/References}

1. Blauvelt $A$, Chiricozzi $A$. The immunologic role of $\mathrm{IL}-17$ in psoriasis and psoriatic arthritis pathogenesis. Clin Rev Allergy Immunol. 2018;55(3):379-390. doi: 10.1007/s12016-018-8702-3

2. Лила А.М., Насонов Е.Л., Коротаева Т.В. Псориатический артрит: патогенетические особенности и инновационные методы терапии. Научно-практическая ревматология. 2018;56(6):685-686 [Lila AM, Nasonov EL, Korotaeva TV. Psoriatic arthritis: pathogenetic features and innovative therapies. Nauchno-Prakticheskaya Revmatologiya = Rheumatology Science and Practice. 2018;56(6):685-691 (In Russ.)] doi: 10.14412/1995-4484-2018-685-691

3. Veale DJ, Fearon U. The pathogenesis of psoriatic arthritis. Lancet. 2018;391(10136):2273-2284. doi: 10.1016/S0140-6736(18)30830-4

4. Taams LS, Steel KJA, Srenathan U, Burns LA, Kirkham BW. $\mathrm{IL}-17$ in the immunopathogenesis of spondyloarthritis. Nat Rev Rheumatol. 2018;14(8):453-466. doi: 10.1038/s41584-018-0044-2

5. Szczerkowska-Dobosz A, Krasowska D, Bartosińska J, StawczykMacieja M, Walczak A, Owczarczyk-Saczonek A, et al. Pathogenesis of psoriasis in the "omic" era. Part IV. Epidemiology, genetics, immunopathogenesis, clinical manifestation and treatment of psoriatic arthritis. Postepy Dermatol Alergol. 2020;37(5):625-634.

doi: 10.5114/ada.2020.100478

6. Wellcome Trust Case Control Consortium. Genome-wide association study of 14,000 cases of seven common diseases and 3,000 shared controls. Nature. 2007;447(7145):661-678. doi: 10.1038/nature05911

7. Fiorillo MT, Paladini F, Tedeschi V, Sorrentino R. HLA Class I or class II and disease association: Catch the difference if you can. Front Immunol. 2017;8:1475. doi: 10.3389/fimmu.2017.01475

8. Busch R, Kollnberger $S$, Mellins ED. HLA associations in inflammatory arthritis: emerging mechanisms and clinical implications. Nat Rev Rheumatol. 2019;15(6):364-381. doi: 10.1038/s41584-019-0219-5

9. Liu B, Shao Y, Fu R. Current research status of HLA in immunerelated diseases. Immun Inflamm Dis. 2021;9(2):340-350.

doi: $10.1002 /$ iid3.416

10. Neefjes J, Jongsma ML, Paul P, Bakke O. Towards a systems understanding of $\mathrm{MHC}$ class I and MHC class II antigen presentation. Nat Rev Immunol. 2011;11(12):823-836. doi: 10.1038/nri3084

11. Trowsdale J, Knight JC. Major histocompatibility complex genomics and human disease. Annu Rev Genomics Hum Genet. 2013;14:301-323. doi: 10.1146/annurev-genom-091212-153455

12. Robinson J, Barker DJ, Georgiou X, Cooper MA, Flicek P, Marsh SGE. IPD-IMGT/HLA Database. Nucleic Acids Res. 2020;48(D1):D948-D955. doi: 10.1093/nar/gkz950

13. Busch R, Kollnberger S, Mellins ED. HLA associations in inflammatory arthritis: emerging mechanisms and clinical implications. Nat Rev Rheumatol. 2019;15(6):364-381. doi: 10.1038/s41584-019-0219-5

14. Marsh SG, Albert ED, Bodmer WF, Bontrop RE, Dupont B, Erlich HA, et al. Nomenclature for factors of the HLA system, 2010. Tissue Antigens. 2010;75(4):291-455. doi: 10.1111/j.1399-0039.2010.01466.x

15. Wieczorek M, Abualrous ET, Sticht J, Álvaro-Benito M, Stolzenberg S, Noé F, Freund C. Major Histocompatibility Complex (MHC) class I and MHC class II proteins: Conformational plasticity in antigen presentation. Front Immunol. 2017;8:292. doi: 10.3389/fimmu.2017.00292
16. Yewdell JW, Bennink JR. The binary logic of antigen processing and presentation to T cells. Cell. 1990;62(2):203-206.

doi: 10.1016/0092-8674(90)90356-j

17. Williamson L, Dockerty JL, Dalbeth N, McNally E, Ostlere S, Wordsworth BP. Clinical assessment of sacroiliitis and HLA-B27 are poor predictors of sacroiliitis diagnosed by magnetic resonance imaging in psoriatic arthritis. Rheumatology (0xford). 2004;43(1):85-88. doi: 10.1093/rheumatology/keg475

18. Lopez-Larrea C, Torre Alonso JC, Rodriguez Perez A, Coto E. HLA antigens in psoriatic arthritis subtypes of a Spanish population. Ann Rheum Dis. 1990;49(5):318-319. doi: 10.1136/ard.49.5.318

19. Liao HT, Lin KC, Chang YT, Chen CH, Liang TH, Chen WS, et al. Human leukocyte antigen and clinical and demographic characteristics in psoriatic arthritis and psoriasis in Chinese patients. J Rheumatol. 2008;35(5):891-895.

20. Winchester R, Minevich G, Steshenko V, Kirby B, Kane D, Greenberg DA, et al. HLA associations reveal genetic heterogeneity in psoriatic arthritis and in the psoriasis phenotype. Arthritis Rheum. 2012;64(4):1134-1144. doi: 10.1002/art.33415.

21. Бадокин В.В., Трошкина И.А., Гусева И.А. Значение генетической компоненты в клинической презентации псориатического артрита. Доктор.Py. 2012;2(70):44-49 [Badokin VV, Troshkina IA, Guseva IA. Psoriatic arthritis: Role of genetic component in disease's clinical manifestation. Doktor.ru. 2012;2(70):44-49 (In Russ.)]

22. Elkayam 0, Segal R, Caspi D. Human leukocyte antigen distribution in Israeli patients with psoriatic arthritis. Rheumatol Int. 2004;24(2):93-97. doi: $10.1007 / \mathrm{s} 00296-003-0325-0$

23. Chandran V, Tolusso D, Cook R, Gladman D. Risk factors for axial inflammatory arthritis in patients with psoriatic arthritis. J Rheumatol. 2010;37(4):809-815. doi: 10.3899/jrheum.091059

24. Suarez-Almazor ME, Russell AS. Sacroiliitis in psoriasis: relationship to peripheral arthritis and HLA-B27. J Rheumatol. 1990;17(6):804-808

25. Queiro R, Sarasqueta C, Belzunegui J, Gonzalez C, Figueroa M, Torre-Alonso JC. Psoriatic spondyloarthropathy: a comparative study between HLA-B27 positive and HLA-B27 negative disease. Semin Arthritis Rheum. 2002;31(6):413-418. doi: 10.1053/sarh.2002.33470

26. Mazzanti G, Coloni L, Desabbata G, Paladini G. Is HLA B27 a true marker of axial involvement in psoriatic arthropathy? Acta Derm Venereol Suppl (Stockh). 1994;186:71-72.

27. Winchester R, Giles J, Jadon D, Haroon M, McHugh N, FitzGerald 0. Implications of the diversity of class I HLA associations in psoriatic arthritis. Clin Immunol. 2016;172:29-33. doi: 10.1016/j.clim.2016.07.019

28. Haroon M, Winchester R, Giles JT, Heffernan E, FitzGerald 0 . Clinical and genetic associations of radiographic sacroiliitis and its different patterns in psoriatic arthritis. Clin Exp Rheumatol. 2017;35(2):270-276.

29. Haroon M, Winchester R, Giles JT, Heffernan E, FitzGerald 0 . Certain class I HLA alleles and haplotypes implicated in susceptibility play a role in determining specific features of the psoriatic arthritis phenotype. Ann Rheum Dis. 2016;75(1):155-162. doi: 10.1136/annrheumdis-2014-205461

30. Polachek A, Cook R, Chandran V, Abji F, Gladman D, Eder $\mathrm{L}$. The association between HLA genetic susceptibility markers 
and sonographic enthesitis in psoriatic arthritis. Arthritis Rheumatol. 2018;70(5):756-762. doi: 10.1002/art.40423

31. Eastmond CJ. Psoriatic arthritis: genetics and HLA antigens. Baillieres Clin Rheumatol. 1994;8(2):263-276. doi: 10.1016/s0950-3579(94)80018-9

32. Gladman DD, Farewell VT, Kopciuk KA, Cook RJ. HLA markers and progression in psoriatic arthritis. J Rheumatol. 1998;25(4):730-733.

33. Trabace S, Cappellacci S, Ciccarone P, Liaskos S, Polito R, Zorzin L. Psoriatic arthritis: a clinical, radiological and genetic study of 58 Italian patients. Acta Derm Venereol Suppl (Stockh). 1994;186:69-70.

34. Espinoza LR, Vasey FB, Oh JH, Wilkinson R, Osterland CK. Association between HLA-BW38 and peripheral psoriatic arthritis. Arthritis Rheum. 1978;21(1):72-75. doi: 10.1002/art.1780210112

35. Murray C, Mann DL, Gerber LN, Barth W, Perlmann S, Decker JL, et al. Histocompatibility alloantigens in psoriasis and psoriatic arthritis: evidence for the influence of multiple genes in the major histocompatibility complex. J Clin Invest. 1980;66(4):670-675. doi: 10.1172/JCI109903

36. Matsumura M, Fremont DH, Peterson PA, Wilson IA. Emerging principles for the recognition of peptide antigens by MHC class I molecules. Science. 1992;257(5072):927-934. doi: 10.1126/science.1323878

37. Bouvier M, Wiley DC. Importance of peptide amino and carboxyl termini to the stability of MHC class I molecules. Science. 1994;265(5170):398-402. doi: 10.1126/science.8023162

38. Zacharias M, Springer S. Conformational flexibility of the MHC class I alpha1-alpha2 domain in peptide bound and free states: a molecular dynamics simulation study. Biophys J. 2004;87(4):2203-2214. doi: 10.1529/ biophysj.104.044743

39. Saini SK, Ostermeir K, Ramnarayan VR, Schuster H, Zacharias M, Springer S. Dipeptides promote folding and peptide binding of $\mathrm{MHC}$ class I molecules. Proc Natl Acad Sci USA. 2013;110(38):15383-15388. doi: 10.1073/pnas.1308672110

40. Abualrous ET, Saini SK, Ramnarayan VR, Ilca FT, Zacharias M, Springer S. The carboxy terminus of the ligand peptide determines the stability of the MHC class I molecule H-2Kb: a combined molecular dynamics and experimental study. PLoS One. 2015;10:e0135421. doi: 10.1371/journal. pone.0135421

41. Sarkizova S, Klaeger S, Le PM, Li LW, Oliveira G, Keshishian H, Hartigan CR, et al. A large peptidome dataset improves HLA lass I epitope prediction across most of the human population. Nat Biotechnol. 2020;38(2):199-209. doi: 10.1038/s41587-019-0322-9

42. Rammensee HG, Friede T, Stevanoviic S. MHC ligands and peptide motifs: first listing. Immunogenetics. 1995;41(4):178-228. doi: 10.1007/BF00172063

43. Taurog JD. The mystery of HLA-B27: if it isn't one thing, it's another. Arthritis Rheum. 2007;56(8):2478-2481. doi: 10.1002/art.22807.

44. Khan MA, Mathieu A, Sorrentino R, Akkoc N. The pathogenetic role of HLA-B27 and its subtypes. Autoimmun Rev. 2007;6(3):183-189. doi: 10.1016/j.autrev.2006.11.003

45. D'Amato M, Fiorillo MT, Carcassi C, Mathieu A, Zuccarelli A, Bitti PP, et al. Relevance of residue 116 of HLA-B27 in determining susceptibility to ankylosing spondylitis. Eur J Immunol. 1995;25(11):31993201. doi: 10.1002/eji.1830251133

46. Madden DR. The three-dimensional structure of peptide-MHC complexes. Annu Rev Immunol. 1995;13:587-622.

doi: 10.1146/annurev.iy.13.040195.003103

47. Ziegler A, Loll B, Misselwitz R, Uchanska-Ziegler B. Implications of structural and thermodynamic studies of HLA-B27 subtypes exhibiting differential association with ankylosing spondylitis. Adv Exp Med Biol. 2009;649:177-195. doi: 10.1007/978-1-4419-0298-6_13

48. Fabian H, Huser $H$, Loll B, Ziegler A, Naumann D, UchanskaZiegler B. HLA-B27 heavy chains distinguished by a micropolymorphism exhibit differential flexibility. Arthritis Rheum. 2010;62(4):978-987. doi: 10.1002/art.27316
49. Crux NB, Elahi S. Human leukocyte antigen (HLA) and immune regulation: how do classical and nonclassical HLA alleles modulate immune response to human immunodeficiency virus and hepatitis $C$ virus infections? Front Immunol. 2017;8:832. doi: 10.3389/fimmu.2017.00832

50. Lenart I, Guiliano DB, Burn G, Campbell EC, Morley KD, Fussell $H$, et al. The MHC class I heavy chain structurally conserved cysteines 101 and 164 participate in HLA-B27 dimer formation. Antioxid. Redox Signal. 2012;16(1):33-43. doi: 10.1089/ars.2010.3693

51. Bird LA, Peh CA, Kollnberger S, Elliott T, McMichael AJ, Bowness P. Lymphoblastoid cells express HLA-B27 homodimers both intracellularly and at the cell surface following endosomal recycling. Eur $\mathrm{J}$ Immunol. 2003;33(3):748-759. doi: 10.1002/eji.200323678

52. Kollnberger S, Bird L, Sun MY, Retiere C, Braud VM, McMichael A, Bowness P. Cell-surface expression and immune receptor recognition of HLA-B27 homodimers. Arthritis Rheum. 2002;46(11):29722982. doi: 10.1002/art.10605

53. MacLean L, Macey $M$, Lowdell $M$, Badakere $S$, Whelan $M$, Perrett D, Archer J. Sulphydryl reactivity of the HLA-B27 epitope: accessibility of the free cysteine studied by flow cytometry. Ann Rheum Dis. 1992;51(4):456-460. doi: 10.1136/ard.51.4.456

54. Navid F, Colbert RA. Causes and consequences of endoplasmic reticulum stress in rheumatic disease. Nat Rev Rheumatol. 2017;13(1):2540. doi: 10.1038/nrrheum.2016.192

55. Powis SJ, Colbert RA. Editorial: HLA-B27: The story continues to unfold. Arthritis Rheumatol. 2016;68(5):1057-1059. doi: 10.1002/art.39566

56. Dong W, Zhang Y, Yan M, Liu H, Chen Z, Zhu P. Upregulation of $78-\mathrm{kDa}$ glucose-regulated protein in macrophages in peripheral joints of active ankylosing spondylitis. Scand J Rheumatol. 2008;37(6):427-434. doi: 10.1080/03009740802213310

57. Guiliano DB, North H, Panayoitou E, Campbell EC, McHugh K, Cooke $F G$, et al. Polymorphisms in the F pocket of HLA-B27 subtypes strongly affect assembly, chaperone interactions, and heavy-chain misfolding. Arthritis Rheumatol. 2017;69(3):610-621.

doi: 10.1002/art.39948

58. Jeanty C, Sourisce A, Noteuil A, Jah N, Wielgosik A, Fert I, Breban $M$, et al. HLA-B27 subtype oligomerization and intracellular accumulation patterns correlate with predisposition to spondyloarthritis. Arthritis Rheumatol. 2014;66(8):2113-2123. doi: 10.1002/art.38644

59. Tedeschi V, Paldino G, Paladini F, Mattorre B, Tuosto L, Sorrentino R, et al. The impact of the 'mis-peptidome' on HLA class I-mediated diseases: Contribution of ERAP1 and ERAP2 and effects on the immune response. Int J Mol Sci. 2020;21(24):9608. doi: 10.3390/ijms21249608

60. Colbert RA, Navid F, Gill T. The role of $H L A-B{ }^{*} 27$ in spondyloarthritis. Best Pract Res Clin Rheumatol. 2017;31(6):797-815. doi: 10.1016/j.berh.2018.07.012

61. Dangoria NS, DeLay ML, Kingsbury DJ, Mear JP, UchanskaZiegler B, Ziegler A, et al. HLA-B27 misfolding is associated with aberrant intermolecular disulfide bond formation (dimerization) in the endoplasmic reticulum. J Biol Chem. 2002;277(26):23459-23468.

doi: 10.1074/jbc.M110336200

62. Rahmati S, Tsoi L, O'Rielly D, Chandran V, Rahman P. Complexities in Genetics of Psoriatic Arthritis. Curr Rheumatol Rep. 2020;22(4):10. doi: 10.1007/s11926-020-0886-x

63. Caputo V, Strafella C, Termine A, Dattola A, Mazzilli S, Lanna C, et al. Overview of the molecular determinants contributing to the expression of Psoriasis and Psoriatic Arthritis phenotypes. J Cell Mol Med. 2020;24(23):13554-13563. doi: 10.1111/jcmm.15742

64. Patrick MT, Stuart PE, Raja K, Gudjonsson JE, Tejasvi T, Yang J, et al. Genetic signature to provide robust risk assessment of psoriatic arthritis development in psoriasis patients. Nat Commun. 2018;9(1):4178. doi: 10.1038/s41467-018-06672-6 
Участие авторов: все авторы внесли существенный вклад в проведение поисково-аналитической работы и подготовку статьи, прочли и одобрили финальную версию до публикации.

Концепция и дизайн статьи, одобрение окончательной версии статьи - А.А. Кубанов; анализ литературы, сбор и обработка материала, написание текста статьи - В.В. Чикин; концепция, дизайн, подготовка текста статьи - А.Э. Карамова; концепция, дизайн, подготовка текста статьи - Л.Ф. Знаменская; анализ литературы, сбор и обработка материала, написание текста статьи - 0.Г. Артамонова; анализ литературы, сбор и обработка материала, подготовка текста статьи — Д.А. Вербенко.

Authors' participation: all authors made a significant contribution to the search and analytical work and preparation of the article, read and approved the final version before publication.

Concept and design, final approving the article - Alexey A. Kubanov; literature analysis, data collection, analysis, and interpretation, writing an article - Vadim V. Chikin; concept and design development, data analysis and interpretation, writing an article — Arfenya E. Karamova; data analysis and interpretation, writing an article — Lyudmila F. Znamenskaya; literature analysis, data collection, analysis, and interpretation, writing an article Olga G. Artamonova; data collection, analysis, and interpretation, writing an article — Dmitry A. Verbenko.

\section{Информация об авторах}

*Артамонова Ольга Григорьевна - младший научный сотрудник; адрес: Россия, 107076, Москва, улица Короленко, д. 3, стр. 6; ORCID iD: https://orcid.org/0000-0003-3778-4745; eLibrary SPIN: 3308-3330; e-mail: artamonova_olga@list.ru

Кубанов Алексей Алексеевич - д.м.н., просрессор, член-корреспондент PAH; ORCID iD: https://orcid.org/0000-0002-7625-0503; eLibrary SPIN: 8771-4990; e-mail: alex@cnikvi.ru

Чикин Вадим Викторович - д.м.н.; ORCID iD: https://orcid.org/0000-0002-9688-2727; eLibrary SPIN: 3385-4723; e-mail: chikin@cnikvi.ru

Карамова Арфеня Эдуардовна - K.M.H.; ORCID iD: https://orcid.org/0000-0003-3805-8489; eLibrary SPIN: 3604-6491; e-mail: karamova@cnikvi.ru

Знаменская Людмила Федоровна - д.м.H.; ORCID iD: https://orcid.org/0000-0002-2553-0484; eLibrary SPIN: 9552-7850; e-mail: znaml@cnikvi.ru

Вербенко Дмитрий Анатольевич — к.м.н.; ORCID iD: https://orcid.org/0000-0002-1104-7694; eLibrary SPIN: 8261-6561; e-mail: verbenko@gmail.com

\section{Information about the authors}

*Olga G. Artamonova - junior research associate; address: 3 bldg 6, Korolenko street, 107076 Moscow, Russia; ORCID iD: https://orcid. org/0000-0003-3778-4745; eLibrary SPIN: 3308-3330; e-mail: artamonova_olga@list.ru

Alexey A. Kubanov - MD, Dr. Sci. (Med.), Professor, Corresponding Member of the Russian Academy of Sciences; ORCID iD: https://orcid.org/0000-0002-7625-0503; eLibrary SPIN: 8771-4990; e-mail: alex@cnikvi.ru

Vadim V. Chikin — MD, Dr. Sci. (Med.); ORCID iD: https://orcid.org/0000-0002-9688-2727; eLibrary SPIN: 3385-4723; e-mail: chikin@cnikvi.ru

Arfenya E. Karamova - MD, Cand. Sci. (Med.); ORCID iD: https://orcid.org/0000-0003-3805-8489; eLibrary SPIN: 3604-6491; e-mail: karamova@cnikvi.ru

Lyudmila F. Znamenskaya — MD, Dr. Sci. (Med.); ORCID iD: https://orcid.org/0000-0002-2553-0484; eLibrary SPIN: 9552-7850; e-mail: znaml@cnikvi.ru

Dmitry A. Verbenko — MD, Cand. Sci. (Med.); ORCID iD: https://orcid.org/0000-0002-1104-7694; eLibrary SPIN: 8261-6561; e-mail: verbenko@gmail.com

Статья поступила в редакцию: 18.08.2021

Принята к публикации: 10.09 .2021

Дата публикации: 15.10 .2021
Submitted: 18.08 .2021

Accepted: 10.09 .2021

Published: 15.10 .2021 